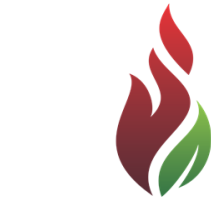

SUSTENERE

Publishing Corporation

\section{MONITORAMENTO DO LIVIXIADO DE COLUNAS DE SOLO APÓS APLICAÇÃO DE VINHAÇA IN NATURA E CONCENTRADA}

\section{RESUMO}

A vinhaça é um efluente líquido com alta carga orgânica e que possui elevadas concentrações de nitrogênio e de potássio. Sua aplicação em doses excessivas, ao longo do tempo, pode ocasionar o acúmulo de elementos do solo nas águas subterrâneas, principalmente a vinhaça concentrada, que apresenta maio concentração de nutrientes em relação à vinhaça in natura. $\mathrm{O}$ objetivo deste trabalho foi avaliar a concentração dos íons nitrato (NO3-) e potássio $(\mathrm{K}+)$ no extrato lixiviado de colunas de solo após a aplicação de vinhaça concentrada e in natura em duas dosagens diferentes. O experimento foi conduzido utilizando-se colunas de percolação de $1,5 \mathrm{~m}$, preenchidas com amostras de Latossolo Vermelho eutrófico coletadas em quatro profundidades $(0-0,2 \mathrm{~m}, 0,2-0,5 \mathrm{~m}, 0,5-0,8 \mathrm{~m}$ e 0,8-1,1 m). As colunas foram construídas com um sistema filtrante na base e, posteriormente, as camadas de solo foram acomodadas de acordo com sua densidade e profundidade reais no campo. Adotou-se o delineamento inteiramente casualizado em parcelas subdivididas com três repetições. Os tratamentos principais, dispostos nas parcelas consistiram de doses e tipos de efluentes assim descritos: $T$ - testemunha absoluta, sem adição de vinhaça; V1 - 150,08 m3 ha-1 de vinhaça in natura; V2 - 300,16 m3 ha-1 de vinhaça in natura; $\mathrm{C} 1$ - 40,01 m3 ha-1 de vinhaça concentrada; $\mathrm{C} 2$ - 80,02 m3 ha-1 de vinhaça concentrada. Os tratamentos secundários (subparcelas) foram épocas de amostragens realizadas semanalmente por um período de 12 semanas.

PALAVRAS-CHAVES: Nitrato; Potássio; Solos Tropicais; Resíduos Agroindustriais.

\section{MONITORING OF LEACHATE SOIL COLUMNS AFTER CONCENTRATED AND IN NATURE VINASSE APPLICATION}

\section{ABSTRACT}

Vinasse is a liquid effluent with a high organic load and has significant concentrations of nitrogen and potassium. Its application in excessive doses, over time, can cause some accumulation and leaching of soil elements to groundwater, especially considering the concentrated vinasse, which has a higher concentration of nutrients in relation to in natura vinasse. The aim of this study was to evaluate the concentration of nitrate ions (NO3-) and potassium $(\mathrm{K}+)$ in the leachate extract collected after application of in natura and concentrated vinasse and in two different strengths. The experiment was conducted in percolation columns with $150 \mathrm{~cm}$ of soil, filled with Oxisol samples collected at four depths $(0-0.2 \mathrm{~m}, 0.2-0.5 \mathrm{~m}, 0.5-0.8 \mathrm{~m}$ and $0.8-1.1 \mathrm{~m})$. The soil columns were constructed in a system filter base and subsequently soil layers were accommodated in accordance with their actual density and depth in the field Completely randomized split plot with three replications was used in this experiment. The main treatments were arranged in plots consisted of four types of effluents and described as follows: T - absolute control, without vinasse; V1 - $150.08 \mathrm{~m} 3 \mathrm{ha}-1$ of in nature vinasse; V2 - 300.16 m3 ha-1 of in nature vinasse; $\mathrm{C} 1-40.01 \mathrm{~m} 3 \mathrm{ha}-1$ of concentrated vinasse; C2 - $80.02 \mathrm{~m} 3$ ha-1 of concentrated vinasse. Secondary treatments (subplots) were conducted weekly sampling dates for a period of 12 weeks. The vinasse doses were established according to the standard CETESB P4.231/2006 The concentrations of ions NO3- and $\mathrm{K}+$ were evaluated in the leachate extract collected for a period of 12 weeks.

KEYWORDS: Nitrate; Potassium; Tropical Soils; Agroindustrial Residues.
Revista Ibero-Americana de

Ciências Ambientais, Aquidabã, v.5, n.2, Jun, Jul, Ago, Set, Out, Nov 2014.

ISSN 2179-6858

SECTION: Articles

TOPIC: Ecologia e Biodiversidade

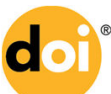

DOI: 10.6008/SPC2179-6858.2014.002.0006

Fabiane Karen Godoy

Serviço Nacional de Aprendizagem Comercial, Brasil http://lattes.cnpq.br/3565007172700007 godoy.fabiane@gmail.com

Simone Daniela Sartorio Universidade Federal de São Carlos, Brasil http://lattes.cnpq.br/5531783544596412 sisartorio@cca.ufscar.br

Marcio Roberto Soares Universidade Federal de São Carlos, Brasil http://lattes.cnpq.br/6337462438517339 mrsoares@cca.ufscar.br

Jose Carlos Casagrande Universidade Federal de São Carlos, Brasil http://lattes.cnpq.br/7227235855217660 bighouse@power.ufscar.br

Received: 18/05/2014

Approved: 15/11/2014

Reviewed anonymously in the process of blind peer.

Referencing this:

GODOY, F. K.; SARTORIO, S. D.; SOARES, M. R. CASAGRANDE, J. C. Monitoramento do livixiado de colunas de solo após aplicação de vinhaça in natura e concentrada. Revista Ibero-Americana de Ciências Ambientais, Aquidabã, v.5, n.2, p.60-72, 2014. DOI: http://dx.doi.org/10.6008/SPC2179$\underline{658.2014 .002 .0006}$ 


\section{INTRODUÇÃO}

A rápida expansão da produção de etanol no Brasil tem exigido soluções efetivas para o gerenciamento da vinhaça, pois tem-se observado a geração de 7 a 16 litros do efluente por litro de etanol produzido (ELIA NETO et al., 2009). Conforme os estudos para ampliação da oferta de biocombustíveis, a produção de etanol no Brasil deverá alcançar aproximadamente 73 bilhões de litros em 2020 (MME, 2011).

No Brasil, praticamente toda a vinhaça é aplicada em solo agrícola por fertirrigação como fonte alternativa de nutrientes para a cana-de-açúcar. A concentração de $\mathrm{K}_{2} \mathrm{O}$ varia de 2.000 a 3.400 $\mathrm{mg} \mathrm{L}^{-1}$ de vinhaça de caldo misto (ELIA NETO et al., 2009) e, em muitas situações, seu uso elimina a necessidade de utilização de fertilizantes potássicos (MAGALHÃES, 2010; WAAl et al., 2009; WHEALS et al., 1999). Essa é uma das razões de muitos estudos sobre o impacto ambiental do uso da vinhaça terem objetivado a dinâmica do K no solo (NUNES et al., 1981; SENGIK et al., 1998; BRITO et al., 2005; BEBÉ et al., 2009). O estudo de Gunkel et al. (2007) mostrou que, em longo prazo, a fertirrigação inadvertida com vinhaça pode levar ao acúmulo de $\mathrm{K}$ no solo e à contaminação de águas superficiais e subterrâneas em níveis toxicologicamente relevantes. Gonzalo et al. (2005; 2006), estudando solos de áreas agrícolas que receberam quantidades arbitrárias de vinhaça por 10 anos consecutivos, observaram que as quantidades de $\mathrm{K}$ variaram de 385 a $2369 \mathrm{~kg}$ de $\mathrm{K}_{2} \mathrm{O}$ na camada de 0-1 m. Amostras de solo coletadas sob os canais de escoamento de vinhaça, à profundidade de 0,8-1 m, apresentaram $9830 \mathrm{~kg} \mathrm{~K}_{2} \mathrm{O}$ ha $^{-1}$. Os efeitos do consumo excessivo de $\mathrm{K}$ são pouco difundidos, mas a hipercalemia é a alteração mais comum do organismo, caracterizada pela diminuição da excreção renal e pelo desbalanço osmótico entre os líquidos intra e extracelular, levando a sérias situações clínicas, tais como a deficiência de insulina e a lise celular (ROCHA, 2009).

Desde 2006, a aplicação da vinhaça em solos agrícolas do Estado de São Paulo deve atender critérios e procedimentos da Norma Técnica P4.231 da CETESB (2006), incluindo a equação de cálculo da dosagem de efluente a ser aplicado $\left(\mathrm{m}^{3} \mathrm{ha}^{-1}\right)$ que considera os teores de $\mathrm{K}$ do solo e da vinhaça e a demanda da cultura pelo elemento. Porém, a vinhaça também possui importantes teores de nitrogênio $(\mathrm{N})$, que podem variar de 330 a $710 \mathrm{mg} \mathrm{L}^{-1}$ de vinhaça de caldo misto. Quando comparado ao íon $\mathrm{K}^{+}$, o ânion nitrato $\left(\mathrm{NO}^{3-}\right)$ possui grande potencial de lixiviação, pois tende a ser repelido pelas cargas negativas do solo. Sua maior mobilidade no perfil pode resultar na poluição das águas subterrâneas e em problemas de saúde pública, pois concentrações acima de $10 \mathrm{mg} \mathrm{L}^{-1}$ de $\mathrm{NO}_{3}^{-}$(CETESB, 2005) permitem a ocorrência de metamoglobinemia (limitações de transporte de oxigênio pelo sangue) e de nitrosaminas e nitrosamidas carcinogênicas no organismo (ALABURDA \& NISHIHARA, 1998).

Existem divergências na literatura científica sobre o potencial de contaminação de águas subterrâneas pela lixiviação de $\mathrm{NO}_{3}{ }^{-}$proveniente de aplicações de vinhaça no solo. Teoricamente, como a quantidade de vinhaça a ser aplicada é calculada com base nos teores de $\mathrm{K}$, o total de $\mathrm{N}$ 
aportado pelo efluente tende a ser absorvido pela cana-de-açúcar e não constitui risco de tornar-se contaminante após sua lixiviação. Contudo, é preciso considerar que a velocidade de lixiviação pode ser incompatível com a taxa de desenvolvimento radicular da cana-de-açúcar. Nesta situação, parte do $\mathrm{NO}_{3}^{-}$pode ser lixiviado para fora da zona de influência das raízes, em direção à água subterrânea. Orlando Filho et al. (1995) avaliaram a lixiviação de $\mathrm{N}$ ao longo do perfil de um Neossolo Quartzarênico sob adubação mineral e aplicação de vinhaça $\left(0,150,300\right.$ e $600 \mathrm{~m}^{3} \mathrm{ha}^{-1}$ $a^{-1}$ ) e concluíram que, no período de 25 semanas após a aplicação do efluente in natura, não houve percolação de $\mathrm{NO}_{3}{ }^{-}$e de $\mathrm{NH}_{4}{ }^{+}$até $2 \mathrm{~m}$ de profundidade. Por outro lado, Cruz e Righetto (1991), em experimento realizado em áreas com diferentes períodos (0, 5, 10 e 15 anos) de aplicação de $300 \mathrm{~m}^{3}$ ha $^{-1}$ ano-1 de vinhaça, notaram violação da potabilidade da água subterrânea pelo aumento da concentração de $\mathrm{NO}_{3}$.

Normalmente, a fertirrigação com vinhaça é realizada nas áreas mais próximas da unidade geradora, pois, a partir de certa distância, a prática torna-se economicamente inviável. Considerando o volume de 876 milhões de litros de vinhaça previstos para serem gerados em 2020, a taxa de aplicação média de $150 \mathrm{~m}^{3} \mathrm{ha}^{-1}$ ano $^{-1}$ conforme a norma P4.231 (CETESB, 2006) e a improvável capacidade de armazenamento em tanques impermeabilizado, é necessário que alternativas inovadoras de manejo do efluente sejam implementadas. A vinhaça concentrada pode ser uma alternativa para diminuir os custos com o transporte em caminhões-tanque para áreas mais distantes. Existem vários estudos sobre o comportamento de vinhaça in natura em solo agrícola, mas ainda é necessário esclarecer a eficiência agronômica e o potencial poluidor da vinhaça concentrada (ROSSETTO, 2010).

Vários autores relataram o emprego bem sucedido de colunas de percolação para o estudo do transporte de solutos no solo em ambiente de laboratório (BOEIRA et al., 2003; BRITO et al., 2007; RIBEIRO et al., 2010; SILVA et al., 2012a). Esta técnica tem a vantagem de possibilitar a obtenção de resultados com grande aplicabilidade em campo, pois o potencial de lixiviação é avaliado mediante a simulação da pluviosidade de determinada região (BOEIRA et al., 2003).

O objetivo deste trabalho foi avaliar, ao longo do tempo, o efeito de tipos e de doses de vinhaça sobre os teores de nitrato e de potássio em extratos lixiviados de colunas de Latossolo Vermelho Eutrófico, aplicadas conforme a Norma Técnica CETESB P4.231/2006.

\section{METODOLOGIA}

O experimento foi instalado e conduzido em ambiente controlado da Universidade Federal de São Carlos, Campus de Araras-SP, utilizando-se material proveniente de um Latossolo Vermelho eutrófico. O solo, representativo da zona canavieira do estado de São Paulo, foi coletado nas profundidades de 0 a 0,2m, 0,2 a 0,5 m, 0,5 a 0,8 m e 0,8 a 1,1 m para a confecção de colunas de percolação para análise de extrato lixiviado. Amostras deformadas, secas ao ar e passadas em 
peneira de malha de $2 \mathrm{~mm}$ foram submetidas à análise química para fins de fertilidade (Quadro 1), conforme métodos de Raij et al. (2001) e de Camargo et al. (2009).

Quadro 1: Atributos químicos do LATOSSOLO VERMELHO Eutrófico utilizado no experimento.

\begin{tabular}{cccccc}
\hline & \multirow{2}{*}{ Parâmetro } & \multicolumn{4}{c}{ Profundidade $(\mathrm{m})$} \\
\cline { 3 - 6 } & & $0,0-0,2$ & $0,2-0,5$ & $0,5-0,8$ & $0,8-1,1$ \\
\hline $\mathrm{P}$ & $\mathrm{mg} \mathrm{dm}^{-3}$ & 4 & 1 & 1 & 1 \\
$\mathrm{M} . \mathrm{O}$. & $\mathrm{g} \mathrm{dm}^{-3}$ & 24 & 17 & 12 & 11 \\
$\mathrm{pH}$ & $\left(\mathrm{CaCl}_{2}\right)$ & 5,9 & 5,6 & 5,9 & 6 \\
$\mathrm{Ca}$ & & 41 & 26 & 17 & 17 \\
$\mathrm{Mg}$ & & 9 & 7 & 7 \\
$\mathrm{H}+\mathrm{Al}$ & $\mathrm{mmol}_{\mathrm{c} \mathrm{dm}}{ }^{-3}$ & 26 & 25 & 21 & 18 \\
$\mathrm{SB}$ & & 52,8 & 35,4 & 23,6 & 24,8 \\
$\mathrm{CTC}$ & & 78,8 & 60,4 & 44,6 & 42,8 \\
$\mathrm{~V}$ & $\%$ & 67 & 59 & 53 & 58 \\
$\mathrm{NO}_{3}{ }^{-}$ & & 34,07 & 19,86 & 10,47 & 13,47 \\
\hline
\end{tabular}

A caracterização física das amostras de solo foi feita segundo os métodos descritos pela Embrapa (1997). Amostras indeformadas de solo foram coletadas com trado tipo Uhland em anéis volumétricos de $50 \mathrm{~cm}^{3}$, para a determinação da densidade aparente (Da) do solo e para a construção da curva de retenção de água, com três pontos a $1500 \mathrm{kPa}$ (limite inferior da água disponível ou ponto de murcha permanente) e a 10 e $30 \mathrm{kPa}$ (limite superior da água disponível ou capacidade de campo) (WARD; TRIMBLE, 2004). Amostras deformadas foram usadas para a análise granulométrica, empregando o método do densímetro (Quadro 2).

Quadro 2: Atributos físicos do LATOSSOLO VERMELHO Eutrófico empregado no preenchimento das colunas de percolação.

\begin{tabular}{|c|c|c|c|c|c|c|}
\hline \multirow{3}{*}{$\begin{array}{l}\text { Camada } \\
\text { (cm) }\end{array}$} & \multirow{3}{*}{$\begin{array}{c}\begin{array}{c}\text { Densidade } \\
\text { aparente } \\
(\mathrm{Da})\end{array} \\
\left(\mathrm{g} \mathrm{cm}^{-3}\right)\end{array}$} & \multicolumn{5}{|c|}{ Análise Granulométrica } \\
\hline & & \multirow{2}{*}{$\begin{array}{c}\text { Argila } \\
(\%)\end{array}$} & \multicolumn{3}{|c|}{ Areia $(\%)$} & \multirow{2}{*}{$\begin{array}{l}\text { Silte } \\
(\%)\end{array}$} \\
\hline & & & Grossa & Fina & Total & \\
\hline $0-20$ & 1,29 & 58,7 & 6,7 & 8,0 & 14,7 & 26,7 \\
\hline $20-50$ & 1,26 & 63,0 & 6,0 & 8,0 & 14,0 & 23,0 \\
\hline $50-80$ & 1,02 & 57,7 & 5,7 & 9,0 & 14,7 & 27,7 \\
\hline $80-110$ & 0,99 & 56,6 & 6,0 & 8,7 & 14,7 & 29,0 \\
\hline
\end{tabular}

\section{Colunas de Percolação}

Para o estudo da lixiviação dos elementos, foram confeccionadas colunas de percolação utilizando-se tubos de PVC de $150 \mathrm{~mm}$ e $170 \mathrm{~cm}$ de altura. Na base, foi montado um sistema filtrante contendo uma camada de $5 \mathrm{~cm}$ de argila expandida, círculos de tela de nylon e pano multiuso intercalados, fixados com arame galvanizado, cola de PVC e silicone. Esta estrutura foi criada a fim de sustentar toda a massa de solo da coluna sem rompimentos. Também foi instalado um dreno para saída da solução lixiviada e um frasco de PET foi colocado para coleta do lixiviado. 
As camadas de solo foram acomodadas de acordo com sua densidade e profundidade reais no campo, até a altura de $150 \mathrm{~cm}$, definida conforme a norma P4.231 (CETESB, 2006), que estabelece a profundidade mínima de $150 \mathrm{~cm}$ para o nível d'água do aquífero livre, no momento da aplicação da vinhaça. O preenchimento das colunas foi iniciado pela base, procedendo-se o empacotamento de modo a simular a densidade do perfil do solo sob as condições de campo (SOARES \& CASAGRANDE, 2009).

Em cada coluna foram adicionados $150 \mathrm{~cm}$ de solo, divididos em quatro partes de acordo com as camadas coletadas em campo. As três primeiras camadas superiores foram acondicionadas nas colunas conforme foram coletadas em campo, respeitando as profundidades. A última camada coletada até $110 \mathrm{~cm}$, entretanto, foi utilizada para preencher os $70 \mathrm{~cm}$ restantes da coluna, totalizando os $150 \mathrm{~cm}$ de solo. Esta metodologia foi usada já que os Latossolos têm pequenas alterações nas propriedades químicas e físicas a partir da profundidade de 1,00 m, não sendo necessário coletar o solo a grandes profundidades.

Antes de receberem vinhaça, as colunas de solo foram saturadas através da ascensão da água, pela parte inferior, local da instalação dos drenos que, posteriormente liberados, permitiram escoar o excesso de água até cessar os efeitos gravitacionais, levando-as, consequentemente, a máxima capacidade de retenção de água contra a ação da gravidade, equivalente à capacidade de campo (CAMBUIM, 1983; BRITO et al., 2007).

\section{Delineamento experimental e fatores em estudo}

Adotou-se delineamento experimental inteiramente casualizado em parcelas subdivididas com três repetições. Os tratamentos principais, dispostos nas parcelas, consistiram de doses e tipos de efluentes assim descritos: $T$ - testemunha absoluta, sem adição de vinhaça; V1 - 150,08 $\mathrm{m}^{3} / \mathrm{ha}$ de vinhaça in natura; V2 - 300,16 $\mathrm{m}^{3} / \mathrm{ha}$ de vinhaça in natura; $\mathrm{C} 1$ - 40,01 $\mathrm{m}^{3} / \mathrm{ha}$ de vinhaça concentrada; $\mathrm{C} 2-80,02 \mathrm{~m}^{3} /$ ha de vinhaça concentrada. Os tratamentos secundários (subparcelas) foram épocas de amostragens realizadas semanalmente por um período de 12 semanas. $A$ vinhaça foi cedida por uma usina de açúcar e álcool do Estado de São Paulo. A partir de um mesmo lote, o efluente foi coletado in natura, diretamente das colunas de destilação a $95^{\circ} \mathrm{C}$, e concentrado por evaporação, diretamente do concentrador da usina. As amostras foram analisadas conforme a norma P4.231 (CETESB, 2006), em laboratório que emprega metodologias acreditadas pela NBR ISO-IEC 17025:2005. As doses de vinhaça foram estabelecidas em função da Norma CETESB P4.231/2006 (Quadro 3).

Quadro 3: Doses de aplicação de vinhaça calculadas de acordo com a norma CETESB P4.231/2006 em cada um dos tratamentos empregados no experimento.

\begin{tabular}{cccccc}
\hline \multirow{2}{*}{ Tratamentos } & $\mathrm{K}_{2} \mathrm{O}$ & \multicolumn{3}{c}{ Dose 1 } & \multicolumn{2}{c}{ Dose 2 } \\
\cline { 3 - 6 } & $\left(\mathrm{Kg} \mathrm{m}^{3}\right)$ & $\mathrm{m}^{3} \mathrm{ha}^{-1}$ & $\mathrm{~mL} /$ coluna & $\mathrm{m}^{3} \mathrm{ha}^{-1}$ & $\mathrm{~mL} /$ coluna \\
\hline In natura $(\mathrm{V})$ & 4,80 & 150,08 & 265,22 & 300,16 & 530,43 \\
Concentrada $(\mathrm{C})$ & 17,80 & 40,57 & 71,69 & 81,14 & 143,39 \\
\hline
\end{tabular}


Quadro 4: Caracterização química da vinhaça in natura e concentrada coletada para o experimento, de acordo com a norma CETESB P4.231/2006.

\begin{tabular}{|c|c|c|c|}
\hline \multirow{2}{*}{ Parâmetro } & \multirow{2}{*}{ Unidade } & \multicolumn{2}{|c|}{ Vinhaça } \\
\hline & & In natura & Concentrada \\
\hline $\mathrm{pH}$ & 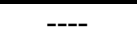 & 4,06 & 4,26 \\
\hline $\mathrm{SST}^{1}$ & $\mathrm{mg} \mathrm{L}^{-1}$ & $3.980,00$ & $40.700,0$ \\
\hline Dureza Total & $\mathrm{mg} \mathrm{L}^{-1}$ & $1.619,90$ & $99.850,6$ \\
\hline $\mathrm{CE}^{2}$ & $\mu \mathrm{S} \mathrm{cm}^{-1}$ & $5.390,0$ & $17.130,0$ \\
\hline Nitrato ${ }^{3}$ & $\mathrm{mg} \mathrm{L}^{-1}$ & 4,689 & 12,155 \\
\hline Nitrito & $\mathrm{mg} \mathrm{L}^{-1}$ & 0,115 & 0,904 \\
\hline $\mathrm{N}-\mathrm{NH}_{3} 4$ & $\mathrm{mg} \mathrm{L}^{-1}$ & 7,54 & 19,89 \\
\hline NK 5 & $\mathrm{mg} \mathrm{L}^{-1}$ & 398,60 & 265,44 \\
\hline Sódio & $\mathrm{mg} \mathrm{L}^{-1}$ & 14,66 & $1.592,20$ \\
\hline Cálcio & $\mathrm{mg} \mathrm{L}^{-1}$ & 398,6 & $15.930,0$ \\
\hline $\mathrm{K}_{2} \mathrm{O}^{6}$ & $\mathrm{~kg} \mathrm{~m}^{3}$ & 4,80 & 17,50 \\
\hline Magnésio & $\mathrm{mg} \mathrm{L}^{-1}$ & 151,68 & $14.588,0$ \\
\hline Sulfato & $\mathrm{mg} \mathrm{L}^{-1}$ & $1.794,62$ & $10.529,28$ \\
\hline Fosfato total & $\mathrm{mg} \mathrm{L}^{-1}$ & 10,74 & 118,16 \\
\hline $\mathrm{DBO}_{5}{ }^{7}$ & $\mathrm{mg} \mathrm{L}^{-1}$ & $23.660,0$ & $72.453,3$ \\
\hline $\mathrm{DQO}^{8}$ & $\mathrm{mg} \mathrm{L}^{-1}$ & $59.150,0$ & $211.200,0$ \\
\hline
\end{tabular}

Análises realizadas por laboratório acreditado pela ISO IEC 17025:2005. ${ }^{1}$ Sólidos Suspensos Totais (Resíduo não filtrável total). ${ }^{2}$ Condutividade Elétrica, ${ }^{3} \mathrm{Análise} \mathrm{por} \mathrm{cromatografia} \mathrm{de} \mathrm{troca} \mathrm{iônica.}{ }^{4}$ Nitrogênio Kjeldhal, ${ }^{5}$ Nitrogênio Amoniacal, ${ }^{6}$ Potássio ${ }^{7}$ Demanda Bioquímica de Oxigênio em 5 dias. ${ }^{8}$ Demanda Química de Oxigênio.

A análise de variância relativa aos dados de $\mathrm{NO}_{3}{ }^{-}$e $\mathrm{K}^{+}$revelou significância para todos os fatores em estudo, inclusive para a interação "vinhaça x tempo". A vinhaça concentrada proporcionou os maiores de K observados no experimento (Figura 1).

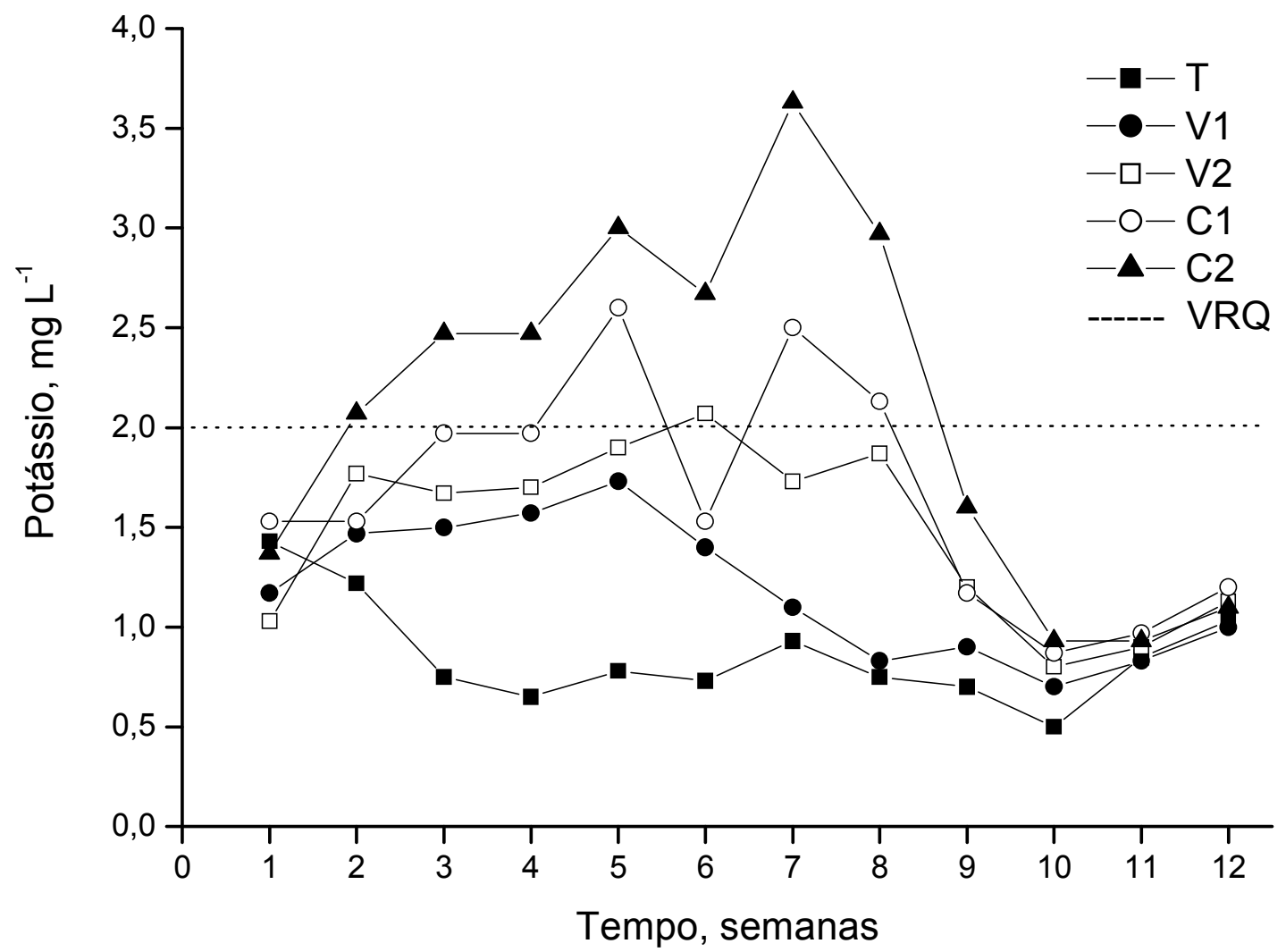

Figura 1: Variações das concentrações de potássio, em $\mathrm{mg} \mathrm{L}^{-1}$, no extrato lixiviado durante 10 semanas de monitoramento.

Testemunha; V1 - Tratamento com vinhaça in natura na dose calculada pela norma P4.231; V2 - Vinhaça Tratamento com vinhaça in natura na dose calculada pela norma P4.231 multiplicada por 2; C1 - Vinhaça concentrada na dose calculada pela norma P4.231; C2 - Vinhaça concentrada na dose calculada pela norma P4.231 multiplicada por 2. VRQ ${ }^{1}$ - Valor de Referência da Qualidade nos aquíferos Tubarão e Serra Geral para potássio: 2 mg L ${ }^{-1}$. 
Uma queda nos valores obtidos na $6^{a}$ semana pode ser explicada pelo aumento da quantidade de água aplicada em relação ao mês anterior simulado, que pode ter diluído a concentração do íon $\mathrm{K}$. As maiores concentrações foram atingidas pelo tratamento com vinhaça concentrada na dose 2 (C2), nas semanas 3, 4, 7 e 8, onde foram maiores que em todos os outros tratamentos com aplicação de vinhaça. Estatisticamente, a média de C2 (3,00 mg L-1) foi igual a de C1 na semana 5, que alcançou $2,60 \mathrm{mg} \mathrm{L}^{-1}$ de $\mathrm{K}$, e ao valor médio de $\mathrm{V} 2$ na semana 6 , que foi de $2,07 \mathrm{mg} \mathrm{L}^{-1}$. As médias do tratamento testemunha foram estatisticamente diferentes nas semanas $3,4,5$ e 6 , e igual a $V 1$ nas semanas 7 e 8 . A partir da semana 9, todos os tratamento tiveram médias iguais, o que mostra que o $\mathrm{K}$ não retido pelo solo percorreu o perfil em 2 meses.

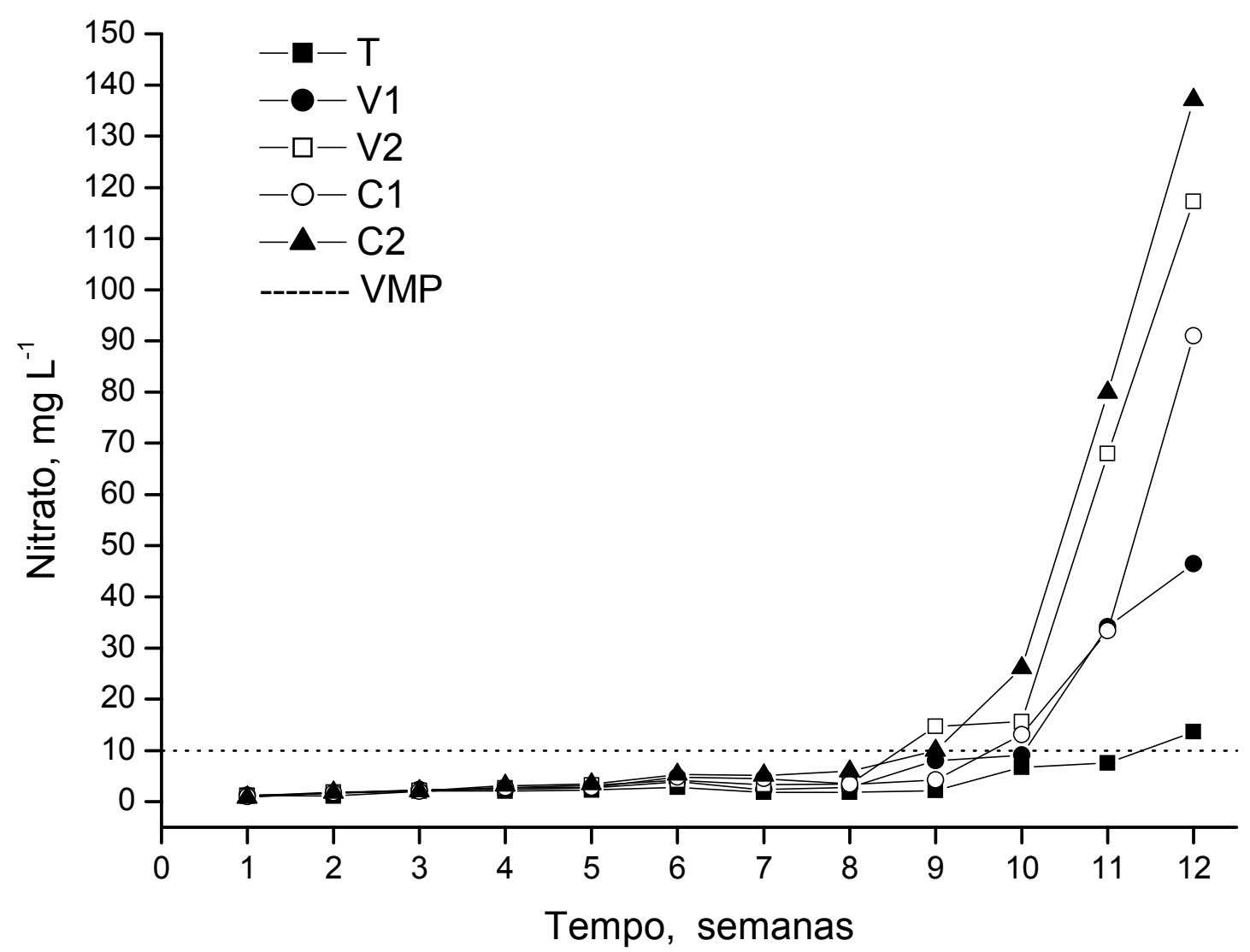

Figura 2: Variações das concentrações de nitrato, em $\mathrm{mg} \mathrm{L}^{-1}$, no extrato lixiviado durante 10 semanas de monitoramento.

Testemunha; V1 - Tratamento com vinhaça in natura na dose calculada pela norma P4.231; V2 - Vinhaça Tratamento com vinhaça in natura na dose calculada pela norma P4.231 multiplicada por 2; C1 - Vinhaça concentrada na dose calculada pela norma P4.231; C2 - Vinhaça concentrada na dose calculada pela norma P4.231 multiplicada por 2. VMP1 - Valor Máximo Permitido para nitrato nas águas subterrâneas pela Lista de Valores Orientadores de Intervenção estabelecidos pela CETESB (2014).

Os maiores valores de nitrato começaram a aparecer na $11^{\mathrm{a}}$ semana após a adição da vinhaça, onde os tratamentos V1 e C1 tiveram médias iguais, da mesma forma que V2 e C2. Na décima segunda semana do experimento, os tratamentos $\mathrm{C} 2$ e V2 apresentaram valores máximos, sendo que os valores médios de $\mathrm{NO}_{3}{ }^{-}$foram de $137 \mathrm{mg} \mathrm{L}^{-1}$, para $\mathrm{C} 2$, e de $117 \mathrm{mg} \mathrm{L}^{-1}$, para V2. $\mathrm{O}$ tratamento $\mathrm{C} 1$ apresentou a segunda maior média, que atingiu $91 \mathrm{mg} \mathrm{L}^{-1}$ (Figura 2).

A alta concentração de $\mathrm{NO}_{3}{ }^{-}$na solução do solo pode estar relacionada à aplicação de grande quantidade de água. A simulação do período de término da safra em outubro, associado a 
precipitação de alta intensidade nos meses seguintes, faz com que os íons $\mathrm{NO}_{3}{ }^{-}$possam ter sua mobilidade intensificada no perfil do solo. A adição de íons $\mathrm{PO}_{4}{ }^{3-}$ e $\mathrm{SO}_{4}{ }^{2-}$, também presentes na vinhaça in natura $\left(10,7\right.$ e 1.794,62 $\left.\mathrm{mg} \mathrm{L}^{-1}\right)$, mas principalmente na vinhaça concentrada $(118,16 \mathrm{e}$ $10.529,3 \mathrm{mg} \mathrm{L}^{-1}$ ) (Quadro 4), pode provocar, além da competição pelos sítios de adsorção, aumento das cargas negativas do solo pela sua própria adsorção (ALCÂNTARA \& CAMARGO, 2005). De acordo com os estudos de Donn e Menzies (2005), quando foi adicionado sulfato ao solo, ele ocupou preferencialmente os sítios de carga positiva, o que resultou em adsorção quase nula e aumentou a lixiviação do nitrato.

\section{RESULTADO E DISCUSSÃO}

Neste contexto, a fertirrigação com vinhaça ao longo do tempo pode ocasionar o acúmulo de $\mathrm{K}$ no solo e o desbalanceamento dos íons, principalmente pela vinhaça concentrada, que apresentou o maior potencial de lixiviação. No entanto, os valores médios de concentração K no lixiviado não foram elevados (Figura 1). O solo empregado neste experimento não havia recebido vinhaça anteriormente. Entretanto, mesmo atendendo às condições estabelecidas pela norma CETESB P4.231/2006 com relação à concentração de $\mathrm{K}^{+}$, ocorreu uma maior lixiviação deste elemento no tratamento $\mathrm{C} 1$, na semana 5. Portanto, pode-se considerar que o potássio teve baixa mobilidade no perfil do solo estudado, já que os valores encontrados no extrato lixiviado foram baixos, não representando grande potencial de alteração dos recursos hídricos. Os tratamentos com vinhaça concentrada e vinhaça in natura na dose 2 contribuíram com altas concentrações de

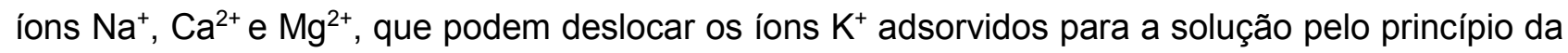
ação das massas (MEURER et al., 2010).

Além disso, a quantidade de $\mathrm{K}^{+}$aportada pelas vinhaças pode superar a capacidade de troca catiônica do solo. Estes fatos, associados à alta quantidade de água adicionada, podem favorecer a mobilidade do íon $\mathrm{K}^{+}$no perfil do solo, mesmo que em pequenas concentrações. A lixiviação de

$K$ depende de sua presença em concentrações significativas na solução do solo, razão por que aumenta com a adição de fertilizantes potássicos e da quantidade de água que percola no perfil. A lixiviação é um fenômeno importante em solos com baixa CTC, especialmente em áreas com alta precipitação pluvial (ERNANI et al., 2007).

Para o nitrato, todos os tratamentos foram estatisticamente iguais até a décima semana de monitoramento. Este fato pode ter ocorrido em função da diminuição dos teores de matéria orgânica com a profundidade em solos tropicais intemperizados, que passam a apresentar de carga positiva nos horizontes subsuperficiais, retardando consideravelmente a lixiviação do $\mathrm{NO}_{3}{ }^{-}$. A presença de cargas positivas é muito maior em solos de regiões tropicais úmidas, com baixos teores de matéria orgânica (MO) e em estádio de intemperismo avançado do que em solos de regiões temperadas. Se as partículas do solo carregarem cargas positivas, a lixiviação do nitrato poderá ser dificultada, embora não totalmente impedida (ALCÂNTARA \& CAMARGO, 2005). 
Os estudos de Oliveira et al. (2000) concluíram que a adsorção de $\mathrm{NO}_{3}{ }^{-}$é sempre maior nos horizontes subsuperficiais do solo, independentemente da sua carga elétrica líquida. Esses autores argumentaram que a maior adsorção de $\mathrm{NO}_{3}{ }^{-}$em subsuperfície está associada com os menores teores de MO do que com qualquer outro fator. Cahn et al. (1992) verificaram que a adsorção de $\mathrm{NO}_{3}{ }^{-}$variou de pequenas quantidades na camada de $0-15 \mathrm{~cm}$ a até $25-50 \%$ na camada $90-120$ $\mathrm{cm}$, ou seja, a adsorção de $\mathrm{NO}_{3}{ }^{-}$aumentou com a profundidade. $\mathrm{O}$ incremento dos teores de $\mathrm{MO}$ em subsuperfície pode deslocar $\mathrm{o} \mathrm{NO}_{3}{ }^{-}$da superfície dos colóides, principalmente por ácidos orgânicos solúveis.

O processo de nitrificação que ocorre no solo apresenta significativa relevância quando da transformação do íon $\mathrm{NH}_{4}{ }^{+}$para $\mathrm{NO}_{2}^{-}$e $\mathrm{NO}_{3}{ }^{-}$, resultando em mudança de carga positiva para negativa (DEMATTÊ, 1992). Como a maior parte da fração coloidal orgânica e inorgânica do solo possui carga negativa, os íons de carga positiva, como $\circ \mathrm{NH}_{4}{ }^{+}$, são atraídos para a sua superfície. Por outro lado, a nitrificação modifica a carga líquida do íon, o que significa que o $\mathrm{NO}_{2}^{-}{\mathrm{e} \mathrm{O} \mathrm{NO}_{3}}^{-}$ podem ser lixiviados rapidamente no perfil do solo até atingir o lençol freático. Este é um processo duplamente comprometedor, uma vez que representa uma perda de formas adsorvidas de $\mathrm{N}$ que poderiam ser assimiladas pelas plantas e transformadas em biomassa e por se constituir em potencial de poluição das águas subterrâneas.

Apesar de não existirem valores de referência de $\mathrm{NO}_{3}{ }^{-}$e de $\mathrm{K}^{+}$para solos, eles estão estabelecidos para as águas subterrâneas. A contribuição de $\mathrm{K}^{+}$encontrada neste experimento supera os Valores de Referência da Qualidade (VRQ) para os aquíferos Tubarão e Serra Geral, de ocorrência na região de Araras - SP, que apresentam $V R Q$ igual a 2,0 $\mathrm{mg} \mathrm{L}^{-1}$ de $\mathrm{K}$ nas suas águas (CETESB, 2010). Ocorreu um aumento gradativo para o nitrato no extrato lixiviado em todos os tratamentos, incluindo o tratamento testemunha, apesar dos valores serem diferentes pelo teste Scott-Knott (Figura 2).

A média de nitrato para o tratamento testemunha foi de $13,64 \mathrm{mg} \mathrm{L}^{-1}$ na semana 12 , ultrapassando o valor máximo permitido (VMP) para as águas subterrâneas pela Lista de Valores Orientadores (CETESB, 2005) que é de $10 \mathrm{mg} \mathrm{NO}_{3}{ }^{-} \mathrm{L}^{-1}$. O solo com água destilada gerou um ambiente com condições propícias ao desenvolvimento da microbiota do solo. A atuação de microorganismos na mineralização e imobilização do nitrogênio presente naturamente no solo podem ter contribuído para o aumento da concentração de $\mathrm{NO}_{3}{ }^{-}$(GARIGLIO, 2008; GODOY et al., 2012).

As concentrações de $\mathrm{NO}_{3}{ }^{-}$determinadas no lixiviado das colunas de solo podem caracterizar poluição das águas subterrâneas, já que alterariam a qualidade do recurso hídrico subterrâneo se a aplicação da vinhaça ocorresse na ausência de cultivo de cana-de-açúcar, ou seja, em área de solo exposto ou em área de sacrifício, ato que ainda ocorre frequentemente em outros estados brasileiros que não tem normas rígidas estabelecidas para controlar a aplicação de vinhaça. Nessas áreas, o solo apresenta maior vulnerabilidade com relação à pluviosidade e não há vegetação ou cultivos para aproveitar os nutrientes da vinhaça.

A partir da semana 9, concentrações de nitrato acima do VMP começaram a aparecer no 
tratamento V2. Mesmo se o tratamento testemunha for considerado como um dado de controle e os valores médios de controle encontrados forem subtraídos dos valores médios dos outros tratamentos, ainda assim os valores de nitrato são maiores e superiores ao VMP nos tratamentos onde foram adicionadas as vinhaças in natura e concentrada. Esta seria a principal evidência de que o nitrogênio disponibilizado pela vinhaça foi transformado em formas mais propensas à lixiviação, como o nitrito e o nitrato.

Desta forma, pode-se identificar a importância da norma P4.231 (CETESB, 2006), já que quando foi aplicada a dose de vinhaça calculada pela norma, no tratamento $\mathrm{V} 1$, com vinhaça in natura, a concentração de $\mathrm{NO}_{3}{ }^{-}$média foi a menor encontrada na $12^{\mathrm{a}}$ semana e foram encontrados os menores valores para $\mathrm{K}^{+}$, que não alcançou 2,0 $\mathrm{mg} \mathrm{L}^{-1}$. Estudos mais aprofundados devem ser desenvolvidos para avaliar o real potencial poluidor da vinhaça concentrada, já que nestes tratamentos foram encontrados os maiores valores para $\mathrm{NO}_{3}{ }^{-} \mathrm{e} \mathrm{K}^{+}$. Estudos mais detalhados, inclusive com experimentos de campo, devem ser estimulados para avaliar o real comportamento da vinhaça no solo e o uso racional deste importante efluente na agricultura.

\section{CONCLUSÕES}

Ocorreu aumento das concentrações de $\mathrm{NO}_{3}{ }^{-}$de $\mathrm{K}^{+}$no lixiviado das colunas de solo após a adição de vinhaça in natura e concentrada: (i) O potássio teve baixa mobilidade no perfil das colunas quando comparado ao comportamento do íon nitrato, que tive maior mobilidade, já que as maiores concentrações foram obtidas no lixiviado; (ii) Nos tratamentos com vinhaça concentrada, os valores de $\mathrm{NO}_{3}{ }^{-}$de $\mathrm{K}^{+}$foram mais elevados; (iii) No tratamento com vinhaça in natura na dose calculada pela norma CETESB, as concentrações dos íons de estudo não ultrapassam os valores de referência de qualidade para águas subterrâneas para $\mathrm{K}^{+} \mathrm{e}$ apresentou os menores valores para $\mathrm{NO}_{3}{ }^{-}$

\section{AGRADECIMENTOS}

À FAPESP, pela concessão de bolsa ao primeiro autor (processo n. 2011/04145-8).

\section{REFERÊNCIAS}

ALABURDA, J ; NISHIHARA, L.. Presença de compostos de nitrogênio em águas de poços. Revista de Saúde Pública, São Paulo, v.32, p.160-165, 1998.

ALCÂNTARA, M.A.K.; CAMARGO, O. A.. Adsorção de nitrato em solos com cargas variáveis. Pesquisa Agropecuária Brasileira, Brasília, v.40, n. 4, p. 369-376, 2005.

BEBÉ, F. V.; ROLIM, M. M.; PEDROSA, E. M. R.; SILVA, G. B.; OLIVEIRA, V. S.. Avaliação de solos sob diferentes períodos de aplicação com vinhaça. Revista Brasileira Engenharia Agrícola Ambiental, Campina Grande, v.13, n.6, p.781-787, 2009. 
BOEIRA, R. C.; DE SOUZA, M. D. ; FERRACINI, V. L.. Utilização de colunas de solo para avaliação da lixiviação de agrotóxicos. In: CONGRESO VIRTUAL IBEROAMERICANO SOBRE GESTIÓN DE CALIDAD EM LABORATORIOS, 2. Anais. Resúmenes. Valladolid: ITACYL, 2003.

MME. Plano Decenal de Expansão de Energia 2020. Brasília: MME/EPE, 2011.

BRITO, F. L.; ROLIM, M. M.; PEDROSA, E. M.. Teores de potássio e sódio no lixiviado e em solos após a aplicação de vinhaça. Revista Brasileira Engenharia Agrícola Ambiental, Campina Grande, v.9, p.52-56, 2005.

BRITO, F. L.; ROLIM, M. M.; PEDROSA, E. M.. Concentração de cátions presentes no lixiviado de solos tratados com vinhaça. Engenharia Agrícola, Jaboticabal, v.27: n.9, p.773-781, 2007.

CAMBUIM, F. A.. A ação da vinhaça sobre a retenção de umidade, $\mathrm{pH}$, acidez total, acumulação e lixiviação de nutrientes, em solo arenoso. Dissertação (Mestrado em Ciência do Solo) - Universidade Federal Rural de Pernambuco, Recife, 1983.

CAMARGO, O. A.; BERTON, R. S.; GERALDI, R. N.; SILVA, J. M. A.. Alterações de características químicas de um Latossolo Roxo distrófico incubado com resíduos da indústria álcool-açúcareira. Bragantia, Campinas, v.43, n.1, p.125-139, 1984.

CAMARGO, O. A.; MONIZ, A. C.; JORGE, J. A.; VALADARES, J. M. A. S.. Métodos de Analise Química, Mineralógica e Física de Solos do Instituto Agronômico de Campinas. Campinas: Instituto Agronômico, 2009.

CAHN, M. D.; BOULDIN, D. R.; CRAVO, M. S.. Nitrate sorption in the profile of acid soil. Plant Soil, Amsterdam, v.143, p.179-183, 1992.

CETESB. Norma Técnica P 4.231. Vinhaça: critérios e procedimentos para aplicação no solo agrícola. São Paulo: CETESB, 2006.

CETESB. Decisão de diretoria $n^{\circ}$ 045/2014/e/c/i, de 20 de fevereiro de 2014. Valores orientadores para solo e água subterrânea no Estado de São Paulo - 2014. São Paulo: CETESB, 2014.

CETESB. Relatório de qualidade das águas subterrâneas no Estado de São Paulo - 2007-2009. São Paulo: CETESB, p.218-219, 2010.

CONAB. Acompanhamento de safra brasileira: cana-de-açúcar, primeiro levantamento. Brasília: CONAB, 2013.

CRUZ, R. L.; RIGHETTO, A. M.; NOGUEIRA, M. A.. Experimental investigation of soil and groundwater impacts caused by vinasse disposal. Water Science Technology, v.24, n.11, p.77-85, 1991.

DEMATTÊ, J. L. I.. O Uso Agronômico de Resíduos e Fertilizantes na Cultura da Cana-de-açúcar. In: DECHEN, A. R.; BOARETO, A. E.; VERDADE, F. C.. In: REUNIÃO BRASILEIRA DE FERTILIDADE DO SOLO E NUTRIÇÃO DE PLANTAS, 20. Anais. Campinas: Fundação Cargill, 1992.

DONN,M. J.; MENZIES, N. W.. The effect of ionic strength variation and anion competition on the development of nitrate accumulations in variable charge subsoils. Australian Journal of Soil Research, Victoria, v.43, n.1, p.43-50, 2005.

ELIA NETO, A.; SHINTAKU, A.; DONZELLI, J. L.. Processo agroindustrial. In: ANA; FIESP, UNICA ; CTC. Manual de conservação e reuso de água na agroindústria sucroenergética, Brasília: ANA, cap.4, p.5165, 2009.

EMBRAPA. Manual de métodos de análise de solo. 2 ed. Rio de Janeiro: Embrapa, 1997.

ERNANI, P. R.; ALMEIDA, J. A.; SANTOS, F. C.. Potássio. In: NOVAIS, R. F.; ALVAREZ V. V. H.; BARROS, N. F.; FONTES, R. L. F.; CANTARUTTI, R. B.; NEVES, J. C. L.. Fertilidade do Solo. Viçosa: Sociedade Brasileira de Ciência do Solo, p.551-594, 2007. 
GARIGLIO, H. A. A.. Alterações físicas e químicas e mobilidade de solutos em solos submetidos à aplicação de vinhaça proveniente da fabricação de álcool carburante. Dissertação (Mestrado em Agronomia) - Universidade Federal de Viçosa, Viçosa, 2008.

GODOY, F. K.; SOARES, M. R.; CASAGRANDE, J. C.. Avaliação de um Latossolo Vermelho Eutrófico após incubação com vinhaça. In: REUNIÃO BRASILEIRA DE FERTILIDADE DO SOLO E NUTRIÇÃO DE PLANTAS, 30. Anais. Maceió: SBCS, 2012.

GONZALO, D. D. P.; CASAGRANDE, J. C.; SOARES, M. R.. Lixiviação de potássio em solos adubados com vinhaça. In: CONGRESSO BRASILEIRO DE CIENCIA DO SOLO, 30. Anais. Recife: SBCS, 2005.

GONZALO, D. D. P.; CASAGRANDE, J.; SOARES, M.; MOUTA, E.. Effect of high levels of vinasse application on soil fertility and potash leaching. In: WORLD CONGRESS OF SOIL SCIENCE - FRONTIERS OF SOIL SCIENCE, 18. Proceedings. Filadelphia: WCSS, 2006.

GUNKEL, G.; KOSMOL, J.; SOBRAL, M.; ROHN, H.; MONTENEGRO, S.; AURELIANO, J.. Sugar cane industry as a source of water pollution - case study on the situation in Ipojuca River, Pernambuco, Brazil. Water, Air and Soil Pollution, v.180, p.261-269, 2007.

MAGALHÃES, V. R.. Influência de doses de vinhaça nas características agronômicas de variedades de cana-de-açúcar, cana-planta e atributos químicos. Dissertação (Mestrado em Produção Vegetal no Semiárido) - Universidade Estadual de Montes Claros, Montes Claros, 2010.

MEURER, E. J.; RHENHEIMER, D.; BISSANI, C. A.. Fenômenos de Sorção em Solo. In: MEURER, E.J. Fundamentos de Química do Solo. Porto Alegre: Evangraf, 2010.

NUNES, M. R.; VELLOSO, A. C. X.; LEAL, J. R.. Efeito da vinhaça nos cátions trocáveis e outros elementos químicos do solo. Pesquisa Agropecuária Brasileira, Brasília, v.16, n.2, p.171-176, 1981.

OLIVEIRA, J. R. A.; VILELA, L.; PAULA, J. L.. Adsorção de nitrato em solos do cerrado do Distrito Federal. . Pesquisa Agropecuária Brasileira, Brasília, v.35, n.6, p.1199-1205, 2000.

ORLANDO FILHO, J.; BITTENCOURT, V. C.; ALVES, M. C.. Aplicação de vinhaça em solo arenoso do Brasil e poluição do lençol freático com nitrogênio. STAB Açúcar, Álcool e Subprodutos, Piracicaba, v.13, n.6, p.14-16, 1995.

RAIJ, B.; ANDRADE, J. C.; CARANTELLA, H.; QUAGGIO, J. A.. Análise química para avaliação da fertilidade de solos tropicais. Campinas: Instituto Agronômico de Campinas, 2001.

ROCHA, P. N.. Hipercalemia. Jornal Brasileiro de Nefrologia, São Paulo, v.31, n.1, 2009.

ROSSETTO, R.. Concentrated vinasse use on sugarcane plants: soil chemical attributes, ion lixiviation and agronomic efficiency monitoring. Complete BIOEN Program Folder: FAPESP, 2010.

RIBEIRO, B. T.; LIMA, J. M. D.; GUILHERME, L. R. G.; JULIÃO, L. G. F.. Lead sorption and leaching from an Inceptisol sample amended with sugarcane vinasse. Sciencia Agricola, Piracicaba, v.67, n.4, p.441-447, 2010.

SILVA, N. F.; NETO, J. A. L.; TEIXEIRA, M. B.; CUNHA, F. N.; MIRANDA, J. H.; COELHO, R. D.. Distribuição de solutos em colunas de solo com vinhaça. Brazilian Journal of Irrigation and Drainage, Botucatu, v.1, n.1, p.340-350, 2012.

SILVA, A.; ROSSETTO, R.; BONNECINE, J.; PIEMONTE, M.; MURAOKA, T.. Net and Potential Nitrogen Mineralization in Soil with Sugarcane Vinasse. Sugar Tech, Lucknow, v.15, n.2, p.159-164, 2012.

SENGIK, E.; RIBEIRO, A. C.; CONDE, A. R.. Efeito da vinhaça em algumas propriedades de amostras de dois solos de Viçosa(MG). Revista Brasileira de Ciência do Solo, Viçosa, v.12, n.1, p.11-15, 1988.

SOARES, M. R.; CASAGRANDE, J. C.. Adsorção e modelos. In: RIBEIRO, M. R.; NASCIMENTO, J. R. B.; CANTALICE, M. R.. Tópicos em ciência do solo. Viçosa: Sociedade Brasileira de Ciência do Solo, v.7, p.71-201, 2009.. 
WAAL, A.; JIMÉNEZ-RUEDA, J. R.; BONOTTO, D. M.; BERTELLI, C.; HOFFMANN, H. M.; FOBHAG, E.; SANTILLI, M.. Influence of the vinasse application in sugar cane fields in Patrocínio Paulista, São Paulo State, Brazil. Environmental Health Risk, Southampton, v.14: p.113-124, 2009.

WARD, A. D.; TRIMBLE, S. W.. Environmental Hydrology, 2 ed. Florida: CRC Press LLC, 2004.

WHEALS, A. E.; BASSO, L. C.; ALVES, D. M.; AMORIM, H. V.. Fuel ethanol after 25 years. Trends in biotechnology, Berkeley, v.17, n.12, p.482-487, 1999. 